Hence, for the centre of the earth,

a. a $\mathrm{h} m$ s

First external contact ... June 5 IO 22 I I at $4{ }^{\circ} \cdot 3$ )

from N. towards E. . June 5 io $395^{6}$ at $37 \cdot \dot{8}$

from $\mathrm{N}$. towards $\mathrm{E}$.

Secondinternal contact ... June 5 í $4^{\circ} \quad 6$ at $293^{\circ} \dot{x}$

from N. towards E.

Second external contact ... June 5 i7 $\circ$ o at 290.5

from N. towards $\mathrm{E}$.

And, with the same notation as before, I find for the reduction for parallax,

Ist ext. cont. $=$ June $5 \mathrm{r}$ Ioh $22 \mathrm{~m}$ I Is $+[2 \cdot 4536] \rho \cdot \sin l-[2 \cdot 4582]$ - $\rho \cdot \cos l \cdot \cos \left(\lambda+4 \mathrm{I}^{\circ}-28^{\prime}\right)$.

Ist int. cont. $=J$ une $5^{\prime}$ ioh $39 \mathrm{~m} 56 \mathrm{~s}+[2 \cdot 4838] \rho \cdot \sin l-\left[2 \cdot 455^{8}[\right.$ . p. $\cos l . \cos \left(\lambda+43^{\circ} 52^{\prime}\right)$.

2.21 int. cont. $=\int u n e ~ 5 \mathrm{~d}+6 \mathrm{~h} 42 \mathrm{~m} 6 \mathrm{~s}-[2 \cdot 130 \mathrm{I}] \rho \cdot \sin l+[2 \cdot 5968]$ . $\rho \cdot \cos l \cdot \cos \left(\lambda-10^{\circ} 57^{\prime}\right)$.

and ext. cont. $=$ June $5 \mathrm{~d}$ I $7 \mathrm{~h}$ om os $-\left[\begin{array}{ll}2.1 & 5758] \rho . \sin l+[2.5825]\end{array}\right.$ - $\rho \cdot \cos l \cdot \cos \left(\lambda-6^{\circ} 28^{\prime}\right)$.

At Greenwich the erress only will be visible.

Last internal contact June $\left.\begin{array}{ccccc}5 & \text { at } & \text { r } 6 & 44 & 23\end{array}\right\}$ Mean times at , external , , , at 172 i 75 Greenwich.

The sun will rise at $15 \mathrm{~h} 46 \mathrm{~m}$.

J. R. HIND

\section{AMERICAN NOTES}

THE year I87. $\mathrm{H}$ bids fair to be marked in the history of American science for the great number of exploring expeditions under the auspices of the United States Government. First, that of Captain C. F. Hall, the well-known Arctic travelJer, for whose pioposed Polar Exploration the United States stexmer Periwinkle is now being prepared at the Washington Navy-yard. This vessel, of neaily four hundred tons burden, is said to be very staunch and reliable; and her equipment will be of the best order. It is understood that the expedition will start about the end of May, and that Captain Hall's scientific assistants will be Dr. David Walker, formerly known as the surgeon and physicist of Sir Leopold M'Clintock's expedition in the Fox, and Dr. Emil Bessels, who has seen Arctic service in a Spitzbergen expedition. Dr. F. V. Hayden, long known to the public as a geologist and explorer, continues his labours of the past season, with the aid of an appropriation by Congress of 40,000 dols. His party is now being fitted out; and will be provided with the necessary assistants in all branches of research. His work. will be to the northward of the scene of his last year's explorations. A third expedition is that of Lieutenant G. M. Wheeler, which, under the direction of the War Department, proceeds to explore certain little-known regions of Arizona and Southern Nevada, including the country about the Lower Colorado and Bill Williams Fork. This work will require several years for its completion. Lastly, Major Powell continues his labours during the present season, and expects to make a careful examination of the Canons of Green River as well as of the Colorado. - Attention was called some time ago to the high scientific value of the collection of objects made by the late Dr. Klemm, of Dresden, for use in his " History of the Progress of Human Civilisation;" and it was suggested that in its great extent, and in the harmonious exhibition of illustrations of human art and handicraft in every department, it would constitute an important addition to the means of instruction in the city of New York. An association of parties in Leipsic has accomplished its purchase, at a cost of over ten thousand dollars; and has determined to make it the basis of an international anthropological museum, which, it is expected, will be one of the most complete in the world. Contributions from all parts of the globe, and especially from America, are invited by the committee having the matterin charge, and we trust that the appeal will not be in vain. - Stimulated by the success of the experiment made by the Phiiadelphians in stocking the Delaware River with black bass, some public-spirited gentlemen of Reading, Pennsylvania, have undertaken to try the same experiment in the Schuylkill, and 350 dollars have already been subscribed for that purpose.-The town of Amherst, in Massachusetts, has followed the example of
New York, Philadelphia, Boston, and other places, in intro ducing English sparrows, in the hope of establishing a colony of these birds. - The San Francisco papers are calling attention to specimens of fossil ivory brought from Alaska; and parties are said to be about entering upon the business of collecting it on a large scale. This ivory consists of the tusks of the mammoth or fossil elephant (Elephas primigenizus), the remains of which are extremely abundant in Alaska, but much more so in Siberia, from which latter country, as is well known, an appreciable percentage of all the ivory now used in the arts is obtained.-The College of the City of New York in Twenty-third Street, shows a commendable desire to increase its means of instruction in natural history, and particularly in the department of osteology, the president having succeeded by unremitting effort in obtaining means to secure quite a large number of specimens, among which may be especially mentioned a large slab of stone containing a well-preserved skeleton of the Ichthyosaurus, or fish-like fossil lizard from the Lias of Germany. The specimen is about ten feet long, and, from its perfection and excellence of preservatinn, is justly entitled to consideration.

\section{EXPERIMENTS ON THE. SUCCESSIVE POLA- RISATION OF LIGHT, WITH DESCRIPTION OF A NEW POLARISING APPARATUS *}

THE term successive polarisation was applied by Biot to denote the effects produced when a ray of polarised light is transmitted through a plate of rock-crystal cut perpendicularly to the axis, or through limited depths of certain liquids. In these cases the plane of polarisation is found to be changed on emergence, and differently for each homogeneous ray, so that, when white light is employed, on tiuning the analyser round continuously in one direction different colours successively appear, rising or falling in the scale according to the nature of the substance.

If, while the analyser is turned from left to right, the tints ascend (i.e. follow the order $\mathrm{R}, \mathrm{O}, \mathrm{Y}, \mathrm{G}, \mathrm{B}, \mathrm{P}, \mathrm{V})$, the substance is said to exhibit right-handed successive polarisation, but if the tints descend, the successive polarisation is said to be lefthanded.

These phenomena were satisfactorily explained by Fresnel in the following way. The incident polarised ray, instead of resolving itself into two plane polarised rays at right angles to each other, as in the ordinary cases of dipolarisation, resolves itself in these instances into two circularly polarised rays, one righthanded the other left-handed, which are transmitted with different velocities; each homogeneous ray, thus resolved into two opposite circularly polarised pencils, on emergence composes a ray polarised in a single plane, the deviation of which from the primitive plane of polarisation depends on the difference of phase of the two circularly polarised rays on emergence.

The rotation of the planes of polarisation is from left to right or from right to left, according to whether the right-handed or left-handed circular rays are transmitted with the greater velocity.

The term dipolarisation, proposed by Dr. Whewell to express the bifurcation which a ray of polarised light suffers when it is transmitted through a crystallised plate, is a very appropriate one; but as there are different kinds of such separation, we may designate plane dipolarisation the resolution into two planepolarised rays at right angles to each other, and circular dipolarisation the resolution into two circularly polarised rays, one righthanded the other left-handed. In like manner the term elliptic dipolarisation may be employed to represent the phenomena shown by transmitting a polarised ray through a plate of rockcrystal obliquely to the axis.

The object of the present communication is to make known another means of producing successive polarisation, both righthanded and left-handed, which, equally with the well-known modes, may be proved to arise from the interference of two opposite systems of circularly polarised rays.

The polarising apparatus which I have employed for the experiments I am about to detail is represented by Fig. I.

A plate of black glass, $\mathrm{G}$, is fixed at an angle of $3^{\circ}$ to the horizon. The film to be examined is to be placed on a diaphragm, $\mathrm{D}$, so that the light reflected at the polarising angle from the glass plate shall pass through it at right angles, and after reflection at an angle of $18^{\circ}$ from the surface of a polished silver

From the Proceedings of the Royal Society. 
plate $\mathrm{S}$, shall proceed vertically upwards. $\mathrm{N}$ is a Nicol's prism, or any other analyser, placed in the path of the second reflection. The diaphragm is furnished with a ring, moveable in its own plane, by which the crystallised plate to be examined may be placed in any azimuth. $C$ is a small moveable stand, by means of which the film to be examined may be placed in any azimuth and at any inclination; for the usual experiments this is removed.

If a lamina of quartz cut parallel to the axis, and sufficiently thin to show the colours of polarised light, be placed upon the diaphragm so that its principal section (i.e. the section containing the axis) shall be $45^{\circ}$ to the left of the plane of reflection, on turning the analyser from left to right, instead of the alternation of two complementary colours at each quadrant, which appear in the ordinary polarising-apparatus, the phenomena of successive polarisation, exactly similar to those exhibited in the ordinary

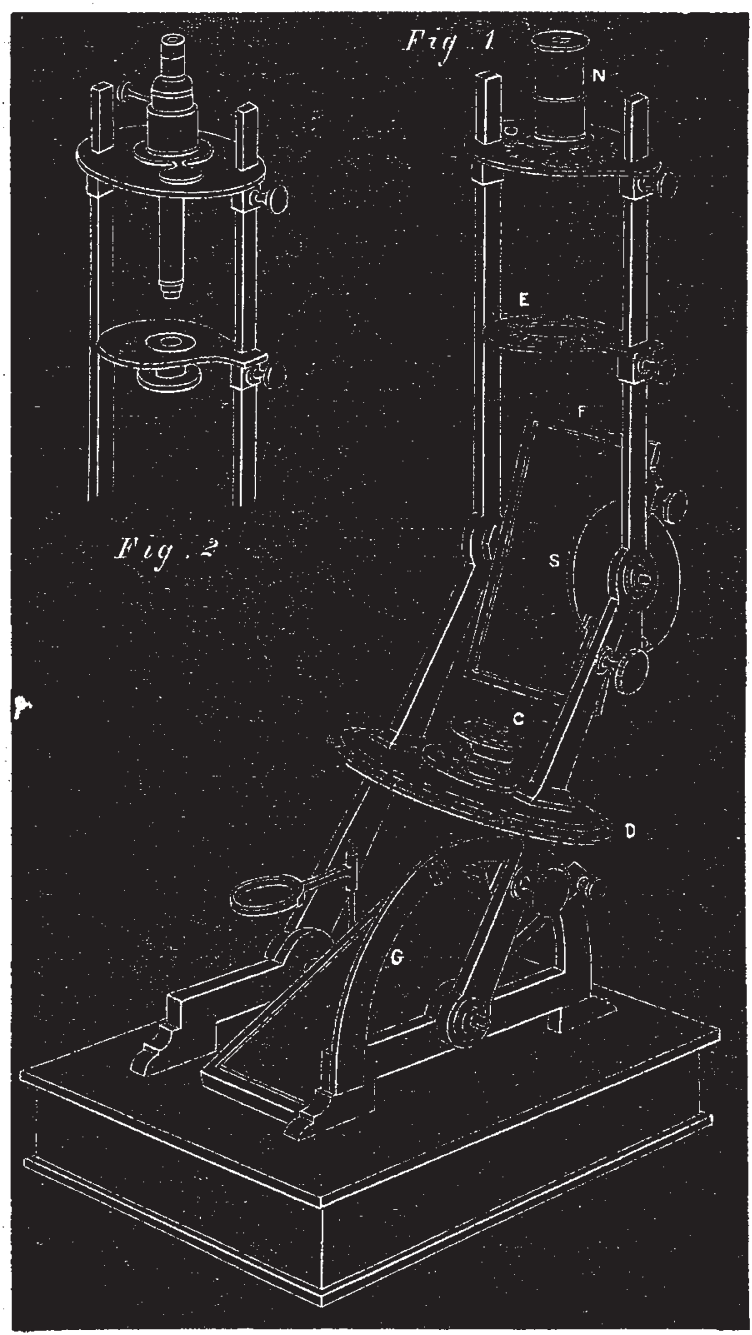

apparatus by a plate of quartz cut perpendicular to the axis will be exhibited: the colours follow in the order $R, O, Y, G$, $\mathrm{B}, \mathrm{P}, \mathrm{V}$, or, in other words, ascend as in the case of a righthanded plate of quartz cut perpendicularly to the axis. If the lamina be now either inverted, or turned in its own plane $90^{\circ}$, so that the principal section shall be $45^{\circ}$ to the right of the plane of reflection, the succession of the colours will be reversed, while the analyser moves in the same direction as before, presenting the same phenomena as a left-handed plate of quartz cut perpendicularly to the axis. Quartz is a positive doubly refracting crystal, and in it consequently the ordinary index of refraction is smaller than the extraordinary index. But if we take a lamina of a negative crystal, in which the extraordinary index is the least, as a film of Iceland spar split parallel to one of its natural cleavages, the phenomena are the reverse of those exhibited by quartz; when the principal section is on the left of the plane of reflection the colours descend, and when it is on the right of the same plane the colours ascend, the analyser being turned from left to right.

It has been determined that the ordinary ray, both in positive and negative crystals, is polarised in the principal section while the extraordinary ray is polarised in the section perpendicular thereto. It is also established that the index of refraction is inversely as the velocity of transmission. It follows from the above experimental results, therefore, that when the resolved ray whose plane of polarisation is to the left of the plane of reflection is the quickest the successive polarisation is right-handed, and when it is the slowest the successive polarisation is left-handed; in the order $\mathrm{R}, \mathrm{O}, \mathrm{Y}, \mathrm{G}, \mathrm{B}, \mathrm{P}, \mathrm{V}$, and in the second case in the reversed order.

The rule thus determined is equally applicable to laminæ of biaxal crystals.

As selenite (sulphate of lime) is an easily procurable crystal, and readily cleavable into thin laminze capable of showing the colours of polarised light, it is most frequently employed in experiments on chromatic polarisation. The laminæ into which this substance most readily splits, contain in their planes the two

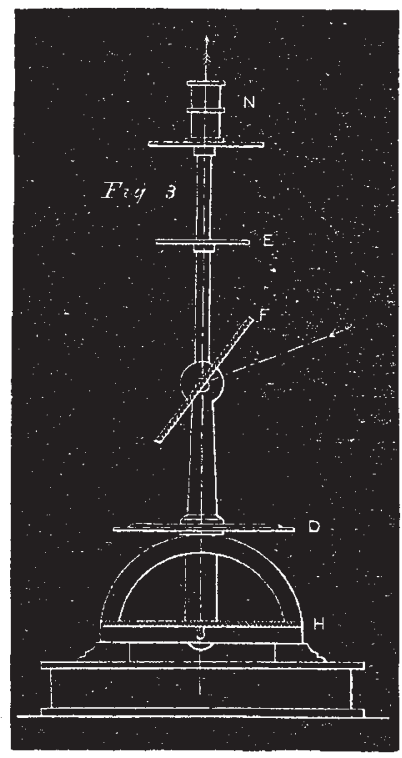

optic axes; polarised light transmitted through such laminæ is resolved in two rectangular directions, which respectively bisect the angles formed by the two optic axes; the line which bisects the smallest angle is called the intermediate section, and the line perpendicular thereto which bisects the supplementary angle is called the supplementary section. These definitions being premised, if a film of selenite is placed on the diaphragm, with its intermediate section to the left of the plane of reflection, the successive polarisation is direct or right-handed ; if, on the contrary, it is placed to the right of that plane, the successive polarisation is left-handed. The ray polarised in the intermediate section is therefore the most retarded; and as that section is considered to be equivalent to a single optic axis, the crystal is positive.

In one kind of mica the optic axes are in a plane perpendicular to the laminæ. They are inclined $22^{\frac{1}{2}}{ }^{\circ}$ on each side the perpendicular within the crystal, but owing to the refraction, are seen respectively at an angle of $35^{\circ} 3$ therefrom.

The principal section is that which contains the two optic axes. If the film is placed on the diaphragm with its principal section inclined $45^{\circ}$ to the left of the plane of reflection, the successive polarisation is right-handed. The ray therefore polarised in the section which contains the optic axes is the one transmitted with the greatest velocity.

Films of uniaxal crystals, whether positive or negative, and of biaxal crystals, all agree therefore in this respect; that if the plane of polarisation of the quickest ray is to the left of the plane 
of reflection, the successive polarisation is right-handed when the analyser moves from left to right, and if it is to the right of the plane of refraction, other circumstances remaining the same, the successive polarisation is left-handed.

It must be taken into consideration that the principal section of the film is inverted in the reflected image, so that if the plane of polarisation of the quickest ray in the film is to the left of the plane of reflection, it is to the right of that plane in the reflected image.

It may not be uninteresting to state a few obvious consequences of this successive polarisation in doubly refracting laminæ, right-handed and left-handed according to the position of the plane of polarisation of the quickest ray. They are very striking as experimental results, and will serve to impress the facts more vividly on the memory.

I. A film of uniform thickness being placed on the diaphragm with its principal section $45^{\circ}$ on either side the plane of refiection, when the analyser is at $0^{\circ}$ or $90^{\circ}$, the colour of the film remains unchanged, whether the film be turned in its own plane $90^{\circ}$, or be turned over so that the back shall become the front surface ; but if the analyser be fixed at $45^{\circ}, 135^{\circ}, 225^{\circ}$, or $315^{\circ}$, complementary colours will appear when the film is inverted from back to front, or rotated in its own plane either way $90^{\circ}$.

2. If a uniform film be cut across and the divided portions be acain placed together, after inverting one of them, a compound film (fig. 4) will be formed, which, when placed on the diaphragm, will exhibit simultaneously both right-handed and left-banded successive polarisation. When the analyser is at $0^{\circ}$ or $90^{\circ}$ the colour of the entire film uniform; as it is turned round the tints of one portion ascend, while those of the other descend; and when the analyser is at $45^{\circ}$ or $n 90^{\circ}+45^{\circ}$, they exhibit complementary colours.

3. A film increasing in thickness from one edge to the other is well suited to exhibit at one glance the phenomena due to films of various thicknesses. It is well known that such a film placed between a polariser and an analyser will show, when the two planes are parallel or perpendicular to each other, and the principal section of the film is intermediate to these two planes, a series of parallel coloured bands, the order of the colours in each band from the thick towards the thin edge being that of their refrangibilities, or $R, O, Y, G, B, P, V$. The bands seen when the planes are perpendicular, are intermediate in position to those seen when the planes are parallel ; on turning round the analyser these two systems of bands alternately appear at each quacrant, while in the intermediate positions they entirely disappear.

Now let us attend to the appearances of these bands when the wedge-form film is placed on the diaphragm of the instrument, Fig. I. As the analyser is moved round the bands advance towards or recede from the thin edge of the wedge without any changes occurring in the colours or intensity of the light, the same tint occupying the same place at every half revolution of the analyser. If the bands advar.ce towards the thin edge of the wedge, the successive polarisation of each point is left-handed; and if they recede from it the succession of colours is right-handed; every circumstance, therefore, that with respect to a uniform film changes right-handed into left-handed successive polarisation, in a wedge of the same substance transforms receding into advancing bands, and vice versic. These phenomena are also beautifully shown by concrve or convex films of selenite or rock-crystal, which exhibit concentric rings contracting or expanding in accordance with the conditions previously explained.

4. Few experiments in physical optics are so beautiful and striking as the elegant pictures formed by cementing laminæ of selenite of different thicknesses (varying from $\frac{1}{2000}$ to $\frac{1}{50}$ of an inch) between two plates of glass. Invisible under ordinary circumstances, they exhibit, when examined in the usual polarising apparatus, the most brilliant colours, which are complemeritary to each other in the two rectangular positions of the analyser. Regarded in the instrument, Fig. I, the appearances are still more beautiful ; for, instead of a single transition, each colour in the picture is successively replaced by every other colour. In preparing such pictures it is necessary to pay attention to the direction of the principal section of each laminæ, when different pieces of the same thickness are to be combined together to form a surface having the same uniform tint; otherwise in the intermediate transitions the colours will be irregularly disposed.

5. A plate of rock-crystal cut perpendicular to the axis loses its successive polarisation, and behaves exactly as an ordinary crystallised film through which rectilinear polarised light is transmitted.
6. A thick plate of unamnealed glass undergoes a series of regular transformation,

The phenomena of successive or rotatury polarisation I have experimentally demonstrated admit of a very simple explanation.

The polarised light incident on the crystallised plate is resolved into two portions of equal in:ensity pularised at right angles to each other, one in the princival section, the other perpendicular thereto. These resolved portions, when they fall on the silver plate, have their planes of polarisation each at an azimuth of $45^{\circ}$, one to the right, the olher to the left of the plane of reflection. These are a ain resulved in the plane of reflection and the plane perpendicular thereto, and are in consequence of the unequal retardation, which in silver at an angle of $72^{\circ}$ amounts to a quarter of an undulation, converted into circularly polarised beams, one right-handed, the other leit-handed.

The various homogeneous rays being accelerated differently in their transmission through the two sections of the crystallised plate this difference is preserved after reflection from the silver plate, and the oppositely circularly pularised beams are reflected with the same difference of phase as the two plane-polarised rays are when emerging from the crystailised lamina. The compusition of two circular waves, one right-handed the other lefthanded, gives for resultant a plane wave, the azimuth of which varies with the difference of phase of the two components.

When the plane of polarisation does not lie equally between the two rectangular sections of the laminæ, these still remaining $45^{\circ}$ from the plane of reflection of the silver plate, the beam is resolved into two unequal portions, the amplitudes of which are as $\sin a$, to $\cos a$.

Each therefore gives rise to a circular undulation of different amplitude. The resultant of two opposite circular undulations of different amplitudes is an ellipse of constant form, the axes of which vary in position according to the difference of phase. The same phenomena of successive polarisation are therefore exhibited in whatever azimuth the lamina is turned in its own plane, but the tints become fainter and fainter until ultimately, when the principal or perpendicular section is parallel to the plane of reflection of the polarising plate, all colour disappears,

By means of the phenomena of successive polarisation it is easy to determine which is the thicker of two films of the same crystalline substance. Place one of the films on the diaphragm (a) of the instrument (Fig. I $a$ ) in the position to show, say, right-handed polarisation, then cross it with the other film; if the former be the thicker, the successive polarisation will be still right-handed ; if both he equal there will be no polarisation; and if the crossed film be the thicker, the successive polarisation will be left-handed. In this manner a series of films may be readily arranged in their proper order in the scale of tints.

In the experiments I have previously described the planes of reflection of the polarising-mirror and of the silver plate were coincident; some of the results obtained when the azimuth of the plane of reflection of the silver plate is changed are interesting.

I will confine my attention here to what takes place when the plane of reflection of the silver plate is $45^{\circ}$ from that of the polarising-reflector.

When the principal sections of the film are parallel and perpendicular to the plane of reflecti in of the polarising mirror, as the whole of the polarised light passes through one of the sectio ns no interference can take place, and no colour will be seen, whatever be the position of the analyser.

When the principal sections of the film are parallel and perpendicular to the plane of reflection of the silver plate, they are $45^{\circ}$ from the plane of reflection of the polarising mirror.

The polarised ray is then resolved into two components polarised at right angles to each other, one component is polarised in the plane of reflection of the silver plate, the other perpendicular thereto; and one is retarded upon the other by a quarter of an undulation.

When the analyser is $0^{\circ}$ or $90^{\circ}$ no colours are seen, because there is no interference; but when it is placed at $45^{\circ}$ or $135^{\circ}$, interference takes place, and the same colour is seen as if light circularly polarised had been passed through the film. 'The bisected and inverted film shows simultaneously the two complementary colours.

But when the film is placed with one of its principal sections $22 \frac{1}{2}^{\circ}$ from the plane of reflection of the polarising-mirror, on turning round the analyser the appearances of successive polarisation are reproduced exactly as when the planes of reflection of the silver plate and of the polarising-mirror coincide. In this 
case the components of the light oppositely polarised in the two sections are unequal, being as $\cos 22 \frac{1}{2}^{\circ}$ to $\sin 22 \frac{1}{2}^{\circ}$; these components respectively fall $22 \frac{1}{2}^{\circ}$ from the plane of reflection of the silver plate and from the perpendicular plane, and are each resolved in the same proportion in these two planes. The weak component of the first, and the strong component of the second, are resolved into the normal plane, while the strong component of the first and the weak component of the second are resolved into the perpendicular plane.

As bearing intimately on the subject of this paper, I will here quote a passage from a memoir presented by Fresnel to the French Academy of Sciences in 1817 , and published, in abstract, in the "Annales de Chimie," t. xxviii., I825:--

"If a thin crystallised plate be placed between two parallelopipeds of glass crossed at right angles, in each of which the light previously polarised undergoes two total reflections at the incidence of $54 \frac{1}{2}^{\circ}$, first before its entrance into the plate (which we suppose perpendicular to the rays), and subsequently after its emergence; and if, besides, the plate be turned so that its axis makes an angle of $45^{\circ}$ with the two planes of double reflection, this system will present the uptical properties of plates of rock crystal perpendicular to the axis, and of liquids which colour polarised light. When the principal section of the rhomboid with which the emergent light is analysed is turned round, the two images will gradually change colour, instead of experiencing only simple variations in the vividness of their tints, as occurs in the ordinary case of thin crystallised plates; besides, the nature of these colours depends only on the respective inclination of the primitive plane of polarisation and the principal section of the rhomboid, that is to say, of the two extreme planes of polarisation; thus, when this angle remains constant, the system of the crystallised plate and the two parallelopipeds may be turned round the transmitted pencil without changing the colour of the images. It is this analogy between the optical properties of this little apparatus and those of plates of rock-crystal perpendicular to the axis which enabled $M$. Fresnel to foresee the peculiar characters of double refraction that rock-crystal exerts on rays parallel to the axis."

It does not appear that Fresnel, in any of his published memoirs, has given any further modifications of this experiment, the importance of which has been almost entirely overlooked in elementary treatises on light. He does nut seem to have remarked that similar phenomena of successive polarisation are exhibited when the light incident on the crystallised plate is plane polarised, nor that the order of the succession of the colours depends on the position of the principal section with respect to the plane of polarisation. These circumstances are indeed necessarily included in the beautiful theory established by this eminent philosopher; but I am not aware that they have hitherto been specifically deduced or experimentally shown.

The apparatus (Fig. I) affords also the means of obtaining large surfaces of uncoloured or coloured light in every state of polarisation, rectilinear, elliptical, or circular.

It is for this purpose much more convenient than a Fresnel's rhomb, with which but a very small field of view can be obtained. It must, however, be borne in mind that the circular and elliptical undulations are inverted in the two methods; in the former case they undergo only a single, in the latter case a double reflection.

For the experiments which follow, the crystallised plate must be placed on the diauhragm $\mathbf{E}$ between the silver plate and the analyser, instead of as in the preceding experiments, between the polariser and the silver plate.

By means of a moving ring within the graduated circle $D$ the silver plate is caused to turn round the reflected ray, so that while the plane of polarisation of the ray remains always in the plane of reflection of the glass plate, it may assume every azimuthal position with respect to the plane of reflection of the silver plate. The film to be exarnined and the analyser move consentaneousiy with the silver plate, while the polarising mirror remains fixed.

In the normal position of the instrument the ray polarised by the mirror is reflected unaltered by the silver plate; but when the ring is turned to $45^{\circ}, 135^{\circ}, 225^{\circ}$, or $315^{\circ}$, the plane of polarisation of the ray falls $45^{\circ}$ on one side of the plane of reflection of the silver plate, and the ray is resolved into two others polarised respectively in the plane of reflection and the perpendicular plane, one of which is retarded on the other by a quarter of an undulation, and consequently gives rise to a circular ray, which is right-handed or left-handed according to whether the ring is turned $45^{\circ}$ and $225^{\circ}$, or $135^{\circ}$ and $315^{\circ}$. When the ring is turned so as to place the plane of polarisation in any intermediate position be-tween those producing rectilinear and circular light, elliptical light is obtained on account of the unequal resolution of the ray into its two rectangular components.

Turning the ring of the graduated diaphragm from left to right when the crystallised film is between the silver plate and the analyser, occasions the same succession of colours for the same angular rotation as rotating the analyser from right to lett when the instrument is in its normal position, and the film is between the polariser and the silver plate.

To arrange the apparatus for the ordinary experiments of plane-polarised light without the intervention of the silver plate, all that is necessary is to remove the silver plate from the frame $\mathrm{F}$, and to substitute for it a plate of black glass, which must be fixed at the proper polarising-angle.

'To convert it into a Norrenberg's polariser, a silver mirror must be laid horizontal at $\mathrm{H}$, and the instrument straightened, as shown at Fig. 3, so that a line perpendicular to the mirror shall correspond with the line of sight. The silver plate must be removed from the frame $F$, and a plate of transparent glass substituted for it, which must be so inclined that the light falling upon it shall be reflected at the polarising-angle perpendicularly towards the horizontal mirror. The eye will receive the polarised ray reflected from the mirror, and the polarised ray will have passed, before it reaches the eye, twice through a crystallised plate placed between the mirror and the polariser. The result is the same as if, in the ordinary apparatus, the polarised plate had passed through a plate of double the thickness.

Fig. 2 shows the addition to the apparatus when the coloured rings of crystals are to be examined by light circularly or elliptically polarised ; $a$ is the optical tube containing the lenses, which require no particular explanation, and $b$ the condenser over which the plate is to be placed.

\section{WhEATS'TONE}

\section{SCIENTIFIC SERIALS}

In the Fournal of Botany for April, Mr. Hiern concludes his exhaustive paper On the Forms and Distribution over the WorId of the Batrachian Section of Ranunculus; Mr. J. G. Baker his Monograph of the Liliaceous genus Xiphion; and we have also the conclusion of the valuable List of New Species of Phanerogamous plants published in Great Britain during the year 1870 , Mr. Hiern's paper concludes with a mathematical statement of the form of the leaf of water-plants dependent on the strength of the current. Mr. Carruthers reviews the Contributions to Fossil Botany published in Britain in 1870 , which are very few in number.

IN the Scottish Naturalist for April, Dr. Lauder Lindsay commences his second paper on Natural Science Chairs in our Universities, and the editor, Dr. Buchanan White, concludes his details of "Sugaring, how, when, and where to do it." Under the head of zoology, Dr. D. Sharp gives an interesting account of the Coleoptera of the Scotch Fir, and Mr. Robert Gray a history of the Capercaillie. The contributions to phytology are a short paper on Scottish plant-names; and a List of Mosses found in the vicinity of Forres, by the Rev. James Keith. Some of the shorter paragraphs contain also interesting information. We would suggest to the conductors of the Naturalist whether it is not possible to avoid the very objectionable practice of dividing their papers in the very middle of a sentence. The present number commences ". . . . waist." in the midst of the Editor's article on Sugaring, and concludes "Knowledge is likely to . . . " in Dr. Lauder Lindsay's on the University Chairs. It is too great a stretch on the memory to expect an incomplete sentence to be kept in the head for three months. and the previous number is not always at hand to remind one of the connection.

\section{SOCIETIES AND ACADEMIES LONDON}

Royal Sociely, April 20.--" Research on a New Group of Colloid Bodies, containing Mercury, and certain members of the series of Fatty Ketones." By J. Emerson Reynolds, M.R.C.P. Edin., \&c.

"On the Existence and Formation of Salts of Nitrous Oxide," By Edward Divers, M.D. 